\title{
Shoppers' grocery choices in the presence of generalized eco-labelling
}

\author{
Yohan BERNARD, University of Franche-Comté \\ Laurent BERTRANDIAS, University of Toulouse \\ Leila ELGAAIED, University of Cergy-Pontoise
}

A slightly improved version of this paper has been accepted in International Journal of Retail and Distribution Management.

To cite : Bernard Y., Bertrandias L. \& Elgaaied L. (2015), Shoppers' grocery choices in the presence of generalized eco-labelling, International Journal of Retail and Distribution

Management, 43, 4/5, 448-468

\section{Structured Abstract}

Purpose - To encourage sustainable consumer practices, public policy makers introduce new ecological measures, including mandatory programs that require companies to provide environmental information about their products, even if not flattering. Few academic studies have considered the potential impact of such mandatory eco-labels on consumer behaviour; this article seeks to identify conditions in which a generalized eco-label in stores might modify consumers' purchase choices.

Methodology-Two quasi-experimental studies $(\mathrm{N}=333,126)$ manipulate environmental information with a simple, traffic light-shaped eco-label. The measures focused on respondents' choice or purchasing intentions, perceptions of the environmental harmfulness of each product, and individual characteristics (i.e., environmental concern, price sensitivity, familiarity with environmental information about the product category).

Findings - The presence of an eco-label influences consumers' beliefs about products' environmental harm and thus choice. The effect of perceived harmfulness on choice is moderated by environmental concern and price sensitivity, though the combinatory effects arise for only one of the two product categories tested (dish soap, not yoghurt). With a third product category (paper towels), Study 2 confirms the influence of familiarity with environmental information.

Research limitations/implications-Familiarity with environmental information accounts for some differences across product categories, but other factors come into play. These results must be interpreted carefully due to the use of a fictive eco-label.

Originality/value - This article examines the potential effects of a generalized, mandatory program. It also addresses the lack of consistent label effectiveness across product categories, with a possible explanation based on perceived familiarity with environmental information. Keywords-environmental labelling, pro-environmental consumer behaviour, perceived harmfulness, environmental concern, price sensitivity, familiarity

Article classification-Research paper 
Consumers have the power to reduce the negative environmental impacts of their consumption by making appropriate choices - an effect they seem to recognise. In a European Commission report (2008), 75 percent of consumers declared themselves ready to buy green products, even at a higher cost. Yet a gap persists between such self-reported intentions and reality. Even if it can be partially explained by social desirability bias, this gap can also be explained by consumers' lack of information and expertise. That is, according to the same report, 42 percent of respondents admitted they could not assess products' potential harmfulness on the basis of existing labels.

The blame does not lie with consumers; for most products, environmental information is still difficult to find and comprehend, especially considering the wide diversity of labels available (D'Souza et al., 2006). The Ecolabel Index lists 440 schemes in 197 countries and 25 industry sectors (http://www.ecolabelindex.com), whose vast numbers and complexity likely confuse consumers. In another recent survey (60 millions de consommateurs, 2013), 62 percent of French consumers acknowledged that they ignored eco-labels, and 89 percent asserted that brands used eco-labels to improve their image. But these trends might change radically if every product available in a grocery store were labelled according to its ecological impact (i.e., more or less negative), such that each label would be clearly favourable (limited negative impact) or unfavourable (greater negative impact). In particular, consumers might orient their choices more toward low-impact products, and ecological product traits likely would interact with other product characteristics, such as price. These suppositions are important, because several realworld experiments address the effect of eco-labelling in Europe, based on initiatives undertaken by retailing groups or partnerships between governments and companies. In turn, there is substantial demand for scientific research that can determine the relevance and potential efficiency of such initiatives. In a compulsory, generalized labelling scheme, all items within a product category would be labelled, whether favourably or unfavourably, and similar information would apply across different product categories. Such an approach seemingly could help consumers gain greater familiarity with environmental information and appraise environmental harmfulness on a relative basis.

This study aims to examine how environmental information provided by a generalized, simple eco-label in stores would influence consumer decision making. We posit that such a label offers an efficient source of information to appraise environmental harmfulness, because the evaluation can be made on a comparative basis. In turn, we seek to determine if consumers would take such easy appraisals of harmfulness into account and why. We start with the supposition that the effect of generalized environmental information on pro-environmental 
choice is stronger in product categories in which consumers already are somewhat familiar with environmental information, and we test this idea in two complementary studies. In addition, we consider the influences of two individual predispositions: environmental concern and price sensitivity. We predict that consumers with strong, enduring concerns for environment degradation feel committed to act in congruence with their perceptions of product harmfulness, whereas price-sensitive consumers may be more likely to make choices independently of their perceptions of potential harm.

In the following sections, we propose a general framework for understanding the effectiveness of generalized eco-labels, including their potential ability to influence consumer choice. We test our hypotheses with Study 1 and confirm them with our complementary Study 2. With an overall discussion, we seek to conclude by putting the results of both studies into perspective.

\section{Generalized eco-labelling in grocery stores: experiences and theoretical perspectives}

Several academic studies have assessed the influence of eco-labels on in-store consumer behaviour (e.g., Bradu et al., 2013; Hoek et al., 2013; Thøgersen et al., 2012; Carrero and Valor, 2012; Vanclay et al., 2011; Thøgersen et al., 2010; Sammer and Wüstenhagen, 2006), though usually by focusing on voluntary labelling schemes, in which a specific brand or retailer implements eco-labels for a limited number of products to highlight their low environmental impact. Thus the tested labels nearly exclusively provide positive environmental information about the products. Some studies consider the notion of negative labels (Grankvist et al., 2004), but to the best of our knowledge, no research examines the impact of a compulsory eco-labelling scheme, providing general information about the environmental impacts of all fast-moving consumer goods (FMCG), even if Caputo et al. (2013) suggest that a mandatory eco-labeling policy would have a positive effect on willingness to pay. Such programs do not currently exist in Europe but are a definite possibility in the future; for example, the European Union energy label already offers a compulsory scheme that provides objective information about the energy consumption associated with light bulbs, white goods and cars. Such tactics could be extended easily to other product categories, to provide more general information about the environmental impact of FMCGs. In France specifically, the opportunity to apply a systematic, unique label to an entire product category is currently under examination.

From an academic view, the experiment conducted by Vanclay et al. (2011), based on the simple, clear carbon labelling of 37 products in a U.S. supermarket, offers an interesting first step. In an eight-week experiment, the authors found limited substitutions due to the labels 
but noted that the market share of unfavourably labelled products decreased significantly. Demand for favourably labelled products increased but only in certain product categories. Their results appear more meaningful when they include the price variable, in that demand for lowcarbon products increased significantly only if the products also were the cheapest options. Similarly, products with high carbon footprints were rejected more when they were also the most expensive. Their experiment suggests that generalized labelling systems induce real but limited changes in demand; it also leaves many questions about the exact mechanisms at work.

More recently, a so-called "heuristics approach" has emerged in the literature. Thøgersen et al. (2012) showed that "green" consumers could choose among several brands of milk at the store based on "green" attributes (revealed by an organic label) relaying on simple choice heuristics or thanks to the adaption of time-proven choice tactics, such as habit. Hoek et al. (2013) extended this result by showing that even sceptical consumers respond strongly to heuristics based on the environmental information conveyed by eco-labels. Consistently, Bradu et al. (2013) found that a traceability label has a significant impact on consumer willingness to buy a chocolate bar. This impact is mediated by moral affective evaluations of the product. They conclude that consumers mainly process the traceability label in a heuristic way. All these recent findings underline the effectiveness of eco-labels to guide consumers' choices in store through a fast and frugal judgment.

A generalized, mandatory eco-labelling system could induce different information processing methods by consumers. In particular, such a label would transform a credence characteristic (environmental harmfulness) into a search attribute that could more readily guide consumers' buying decisions (Sammer and Wüstenhagen, 2006). It also could represent a means to overcome the market failures that occur due to information asymmetries for environmental products. Most existing examples of mandatory labels include information that extends beyond environmental effects though; for example, the EU energy label highlights the cost of using an electric device. In France, another mandatory label informs consumers about the emissions of volatile pollutants for wall and floor coverings and for paints and varnishes, which has implications for environmental preservation but also offers a warranty for consumer health. For grocery products, an eco-label strictly indicates the environmental impact of their production, putting ethical and altruistic considerations at the forefront. Such specificity in turn prompts questions about why consumers adopt or reject pro-environmental behaviours (Park and $\mathrm{Ha}, 2012$ ). Beyond the vast literature investigating the role of various individual determinants, we posit that generalized, mandatory labels would provide consumers with a clear indication of the ecological impact of competing brands in stores. This information could feed 
consumers' beliefs about the environmental consequences of their choices. According to behavioural intention models (Fishbein, 1963), such beliefs may influence brand attitudes and purchase decisions; if a consumer believes that brand $\mathrm{X}$ is more environmentally friendly than brand $\mathrm{Y}$, and this benefit is important, she or he prefers the brand $\mathrm{X}$, ceteris paribus.

Any product may have a more or less negative effect on the environment (e.g., greenhouse gas emissions for transport), so relevant beliefs can be expressed in terms of harmfulness: One product is more or less harmful to the environment. For our study, the key element is consumers' perception of this harm, so we refer to 'perceived harmfulness'. A compulsory eco-label likely is more effective if it influences consumers' perceptions of the environmental harmfulness of competing products too, and when these beliefs in turn affect their purchase choices (see Figure 1).

\section{[Figure 1]}

This approach is consistent with prior literature, which explains pro-environmental behaviours in part by consumers' beliefs. According to Jones's (1991) model of ethical choices, ethical behaviour occurs when a person believes that the situation includes an ethical dimension, which will generate a moral judgment (Hunt and Vitell, 2006). In the VBN model (Stern, 2000), beliefs also lead people to think in terms of norm conformity. In the "heuristics approach" (Bradu et al., 2013; Hoek et al., 2013; Thøgersen et al., 2012), perceived harmfulness would be the piece of information on which the fast, simple judgment could be based on.

H1: When consumers perceive a product in the store as less harmful to the environment than similar, competing products, its purchase probability increases.

\section{Conditional effects of familiarity with environment information}

Labels and environmental signals have grown increasingly widespread for detergents and cleaning products (Pickett-Baker and Ozaki, 2008) and to a lesser extent for seafood products (Wessells et al., 1999; Uchida et al., 2014), but they remain relatively unusual in many other product categories, such as food and beverages. When consumers take environmental preservation into account in their decision-making process, they likely have engaged in some consumer education. In turn, we anticipate that eco-labels should be more efficient in product categories that already have benefited from some pro-environmental education advertising campaigns or that may include some ecological signals on their packaging already. For example, the first campaigns for phosphate-free laundry detergents began in the early 1990s. The recurrent information available in this category should increase consumers' familiarity with the potential environmental harm of such products. Thus, even when consumers recognise a 
signal of environmental harmfulness (H1), their tendency to use the information should vary with the extent to which they consider environmental information relevant for the given product category $(\mathrm{H} 2)$. Both information processing and innovation diffusion theories support this proposition.

\section{Information processing theory}

Familiarity refers to a cognitive representation of past experiences, stored in memory (Marks and Olson, 1981). Consumers who sense familiarity with environmental information about a product category should recall that, in their previous experiences (e.g., purchase, use) information about potential product harmfulness was often present. Familiarity therefore is linked to the number of exposures to information, in line with Alba and Hutchinson's (1987) definition of familiarity. As a type of subjective knowledge (Brucks, 1985), familiarity with environmental information reflects the consumer's feeling of having often encountered information about product harmfulness within a specific product category; similar conceptualisations appear in nutrition research (e.g., Balasubramanian and Cole, 2002). Familiarity in turn is a critical determinant of how consumers process information (Bettman and Park, 1980; Johnson and Russo, 1984; Park and Stoel, 2005). Repeated exposure creates an effect of habituation which involves that initial uncertainty, scepticism, even negativity toward environmental information may be reduced. For example, familiarity with nutrition information stimulates the use of this information, up to a moderate level (Moorman, 1990). Similarly, familiarity with environmental information should help determine the influence of perceived harmfulness on consumers' choices (H2).

\section{Diffusion of innovation theory}

Thøgersen et al. (2010) propose that new labels represent an innovation and therefore use the diffusion of innovation theory to explain consumers' motivations to buy products with new eco-labelling. Consistent with social learning theory (Bandura, 1977), consumers who adopt an innovation at a later stage benefit from social learning, whereas early adopters follow a 'high-effort path'. They note central roles for knowledge and familiarity, in that 'eco-label experience may lead to the learning of a mental script for how to act on knowledge about a new label, which simply speeds up the process of adoption' (Thøgersen et al., 2010 p.1792). We predict that the level of knowledge and familiarity differ depending on the product category.

H2: The effect of environmental information in a generalized eco-label on consumer decisions is stronger when consumers perceive environmental information as familiar in that product category. 


\section{Moderator effects of individual predispositions}

\section{Environmental concern}

Among individual variables, environmental concern is a central determinant of proenvironmental behaviour and therefore the subject of extensive research (e.g., Bamberg, 2003; Mainieri et al., 1997; Tanner and Kast, 2003). Environmentally conscious consumers should be more sensitive to the ecological impact of their consumption (Schwepker and Cornwell, 1991; Schlegelmilch et al., 1996) demand more environmental information about competing products (Brécard et al., 2009) and are more aware of this information when it is provided (Thøgersen, 2000). In turn, we propose that high (low) levels of environmental concern strengthen (attenuate) the link between perceived harmfulness and choice of the least harmful product.

H3. The effect of environmental information in a generalized eco-label on consumer decisions is stronger when consumers are more concerned about the environment.

\section{Price sensitivity}

According to multiple studies, consumers express willingness to pay a premium to obtain environmentally friendly products (e.g., Uchida et al., 2014; Caputo et al., 2013; Casadesus-Masanell et al., 2009; Sammer and Wüstenhagen, 2006), though contradictory results also are available (Delmas and Grant, 2014; Gam et al., 2010). This lack of consensus might stem from consumers' differential price sensitivity (Johnston et al., 2001). Price sensitivity refers to the importance a consumer attaches to price in assessing a product's overall attractiveness or utility (Erdem et al., 2002), so price-sensitive consumers should be more likely to base their purchasing decisions mainly on price, rather than on environmental harmfulness.

H4. The effect of environmental information in a generalized eco-label on consumer decisions is lower when consumers are more price sensitive.

\section{Study 1}

\section{Research design}

In an online pre-test with 128 respondents, we sought to ensure that familiarity with environmental information depended on the product category, then identify two product categories associated with high and low levels of familiarity. Respondents considered several environmental labels, both real and fictitious. We measured their subjective familiarity, with environmental information, defined as a perceived frequency of exposure to environmental information, using two items on a seven-point scale ("According to your past experience, how usual is it to find such environmental information on the packaging of the following products? 
$1=$ very unusual, $7=$ very usual' and 'In the past, how often did you notice such environmental information on the packaging of the following products? $1=$ never or extremely rarely, $7=$ very often'). The questionnaire included five product categories: dishwashing liquid, dry pasta, meat trays, yoghurt and paper towels. The correlations between categories ranged from .45 (for pasta) and .73 (for paper towel), which indicated acceptable internal consistency. The statistically significant differences in familiarity with environmental information across product categories revealed the highest familiarity score for dishwashing liquid and the lowest for yoghurts and dry pasta (see table 1). Paper towels scored in the middle, with the highest standard deviation.

\section{[TABLE 1]}

For the main study, the data collection spanned several French regions through an online survey. France appears to be a rather adequate area for studying the role of familiarity with environmental information. Undoubtedly in France, ecolabelling is viewed as a plus by a lot of companies. For instance, according to European commission statistics on European Ecolabel awards, in January 2012, France has issued $22 \%$ of the total of awards, much less than Italy (about $50 \%$ ), but much more than UK (about $9 \%$ ) or Germany (about $1 \%$ ). In addition and similarly to other countries, consumers are also likely exposed to a wide range of national ecolabels. This profusion gives them the opportunity to get familiar with environmental informational for several product categories, as shown in our pre-test. The sample was elaborated on an empirical basis. This study served as a tutorial in a course of marketing research. 63 undergraduate business students following this course were asked to provide the name, age, gender and a valid email address of 10 of their acquaintances with the watchword to inform the members of their list that they were likely to be contacted by email for that purpose. From this database, about 150 names were removed in order to balance the sample in terms of age and income (that we infer through for a final mailing list of 480 contacts to get closer from national demographic statistics. This adjustment was necessary because of the disputable but well-documented relationship between age or gender and environment concern (e.g. Honnold, 1984; Zelezny et al., 2000).

We developed a between-subject quasi-experimental design manipulating label alternatives on two competing products between which respondents had to choose (see figure 2), coupled with an online questionnaire. We implemented such a manipulation in order to create contrast in perceived harmfulness as it is likely to appear in the context of generalized ecolabelling. We randomly assigned the contacts to the eight cells of the factorial design (see table 2, 60 contact per cell) In the questionnaire they received, participants had to choose between a national brand and a comparable, less expensive store brand, across two product categories, namely, plain 
yoghurt and dish soap, in line with the pre-test results. We created a simple environmental label specifically for this study, representing a three-colour traffic light (red = environmentally harmful, orange $=$ significant but moderate impact, green $=$ environmentally friendly). To introduce the respondents to the label, we asked them to read a short explanation of the study context and the meaning of the presented labelling scheme.

Next, the instructions asked these participants to project themselves into a choice situation described in a short scenario: 'Last time you went shopping you forgot to buy dish soap/plain yoghurt. You stop at a supermarket to pick up the product you need. You hesitate between two products'. At that point, participants saw two comparable products (see Figure 2): a national brand (NB; PAIC for dish soap, Danone for yoghurt) and a store brand (SB; Carrefour in both cases). This configuration offered an easy way to introduce a price difference, so that we could test the potential effect of price sensitivity; price consciousness is a key determinant of consumers' preference for private labels (Glynn and Chen, 2009). For this study, the SB was presented as 35 percent less expensive than the NB. Because SBs often attempt to copy highend NBs, the products in these alternatives also should have appeared very similar to the participants. Each product took a green or a red light label; we excluded orange labels, because our objective was to create contrasts in perceived harmfulness.

[FIGURE 2]

The different label alternatives followed a full factorial design (see Table 2). Respondents were assigned randomly to the different cells. Of the 382 respondents in the main study, 333 noted the traffic light and offered an accurate interpretation of it in response to a control question. They constitute our final sample. It consists of 54 percent women; the average age is 36 years (range 10-75 years). Their average household monthly income amounted to $2800 €$. No association was found between cell affectation and socio-demographics.

[TABLE 2]

\section{Measures}

Perceived harmfulness and manipulation checks. All measures used seven-point Likert scales, ranging from 'strongly disagree' to 'strongly agree'. . Since Perceived environmental harmfulness refers to a belief rather than the actual impact of the product, we captured it using the same approach as most studies measuring environmental beliefs do; by asking respondents to give their level of agreement on different assertions. However, since most existing scales deal with general beliefs about environmental issues (e.g. Kilbourne and Pickett, 2008; Stern et al., 1995), we developed three specific items which focus on consumer's beliefs about the environmental impact of each product presented in our scenario, i.e. "These yogurts are not 
environmentally friendly.", "The production process of these yogurts has a negative impact on the environment.", "On the ecological level, these yogurts do not have a good record.", (NB $\alpha$ $=.93 ; \mathrm{SB} \alpha=.92$ ). The analyses of variance (ANOVA) show that the level of perceived harmfulness for both the NB $(\mathrm{F}=27.94, p<.001)$ and the $\mathrm{SB}(\mathrm{F}=35.27, p<.001)$ depended on the colour of the label (see Figure 2). Tukey post-hoc tests also revealed that harmfulness did not vary significantly between the SB and the NB when the colour of the labelling scheme was the same. Yet perceived harmfulness was slightly but significantly lower for yoghurt than for dish soap, across both the NB $\left(\mathrm{F}=7.45, p<.007 ; \mathrm{M}_{\text {dish }}=4.35, \mathrm{M}_{\text {yoghurt }}=3.87\right)$ and the $\mathrm{SB}$ $\left(\mathrm{F}=5.03, p<.026 ; \mathrm{M}_{\mathrm{dish}}=4.45, \mathrm{M}_{\text {yoghurt }}=4.09\right)$. Environmental information is relatively less common for food products than for dish soap, and it appears that consumers assigned a lower level of environmental harmfulness to these products

Control and moderator variables. We also controlled for three variables: perceived price, perceived quality and attitude toward the brand. For perceived price, we used a one-item scale inspired from Slonim and Gabarino (1999) ('This dish soap/pack of four yoghurts is expensive'). The perceived quality measure featured a three-item scale (e.g., 'The quality of this dish soap/pack of four yoghurts is certainly good'; $\mathrm{NB} \alpha=.87$; $\mathrm{SB} \alpha=.89$ ). Attitude toward the brand was measured by a single indicator adapted from Chattopadhyay and Basu (1991) (e.g., 'PAIC is a good brand of dish soap'). We measured environmental concern using a sixitem scale developed by Kilbourne and Pickett (2008) $(\alpha=.85)$. Finally, price sensitivity was captured with six items revealing price attitudes, picked in three existing scales (Goldsmith and Newel, 1997; Lichtenstein et al., 1993; Netemeyer et al., 1990,) (e.g., 'Price is usually an important criterion I take into account when I shop'; $\alpha=.89$ ). Face validity is secured by the simple and concrete formulations of the items close to the definition of the construct they measure.

\section{Results}

Most respondents chose the SB, which was less expensive (69 percent dish soap, 60 percent yoghurt). We considered the effects of the discrepancies in perceived harmfulness, perceived quality, perceived price and attitude between the national brand $(\mathrm{NB}=0)$ and the store brand $(\mathrm{SB}=1)$. The gap in perceived harmfulness resulted directly from the respondents' processing of information available on the label. We expect its effect to vary as a function of product category, price sensitivity and environment concern. Using binary logistic regressions with the Jonhson-Neyman procedure (Hayes and Mathes, 2009), we obtained the results in Table 3. 
The gap between the two products in terms of perceived harmfulness predicted choices significantly, such that a greater perceived difference increased the probability of choosing the $\mathrm{SB}$ if its perceived harmfulness was lower than the NB's, and vice versa (Model $1 ; \mathrm{B}=.21, p$ $<.001$ ), in line with H1. However, the strength of this association depends on the product category. The interaction between product category and perceived harmfulness revealed a significant impact (Model 2; $\mathrm{B}=-.39, p=.004$ ), such that the effect of the harmfulness discrepancy was not significant for yoghurt $(\mathrm{B}=.04, p=.64)$ but was highly significant for dishwashing liquid $(\mathrm{B}=.43 ; p<.001)$. This finding lends support to $\mathrm{H} 2$. In turn, we performed the moderator analyses only with the dishwashing liquid sub-sample.

\section{[TABLE 3]}

Regarding H3, it appears that environmental concern serves as a moderator: The effect of the interaction of perceived harmfulness and environmental concern is significant and positive (Model 3, $\mathrm{B}=.21, p=.040$ ). In Figure 3, the slope of the curve for high environmental concern is more acute, suggesting that environmentalists are more prone to act consistently with their perception of harmfulness, in line with H3. For consumers with stronger environmental concerns (mean + one SD), a store brand that is perceived as more (less) harmful than the national brand increases the probability of choosing the national brand (store brand) substantially ( $\mathrm{B}=.61, p<.001)$. This effect is not significant for people who express low environmental concern (mean - one $\mathrm{SD} ; \mathrm{B}=.10, p=.55$ ). Furthermore, among highly concerned consumers, we observe that the effect of harmfulness is not linear; the slope of the curve approaches zero when the SB appears much less harmful than the NB. In this configuration, perceived harmfulness has little impact, such that it appears to exert an influence only if consumers can trade off the low price and environmental preservation.

Price sensitivity also moderates the effect of product harmfulness, though differently. The interaction between harmfulness and price sensitivity is significant (Model 4, $\mathrm{B}=-.43, p=$ .026). The effect of perceived harmfulness was not significant among highly price sensitive consumers (mean + one $\mathrm{SD} ; \mathrm{B}=.08, p=.675$ ). We found support for $\mathrm{H} 4$ in the dish soap sample, and these interaction effects remained significant when we included both moderators in the same model (Model 5) to increase its statistical robustness. Using the SPSS script PROCESS (Hayes, 2012) to assess the conditional effect of the difference in perceived harmfulness on choice for different values of the moderator (see Figure 4), we determined that with low price sensitivity, consumers considered product harmfulness if they also were sufficiently concerned about the environment (Mean $+1 \mathrm{SD}, \mathrm{B}=.83, p=.001$; Mean $-1 \mathrm{SD}, \mathrm{B}=.33, p=.135$ ). Among highly price sensitive consumers, perceived harmfulness did not significantly influence 
choices, regardless of their level of environmental concern $(\mathrm{M}+1 \mathrm{SD}, \mathrm{B}=.27, p=.07$; Mean $-1 \mathrm{SD}, \mathrm{B}=.02, p=.856)$. That is, the positive effect of strong environmentalist convictions can be mitigated by high price sensitivity.

[TABLE 4]

[Figures 3 \& 4]

\section{Discussion}

The results of Study 1 indicate that environmental labels have impacts on perceived harmfulness, which in turn influences consumer choice. When consumers perceive substantial discrepancies between competing brands with regard to their environmental impact, they tend to choose the most environmental friendly product. This finding suggests the strong demand for suitable information and educating consumers about sustainable purchasing behaviour. Public policy makers should encourage such practices or even make them mandatory, in the form of massive environmental labelling programs. However, the effectiveness of such labels varies, depending on individual characteristics. For example, consumers of dishwashing liquid are more prone to act consistently with their perceptions of environmental harmfulness when they are already environmentally conscious. Theoretically, this finding is compelling, because few researchers have considered the possible plurality of roles of environmental concern. We reveal that environmental concern not only influences specific attitudes toward green products (Bamberg, 2003) but also modifies the decision to consider available information about environmental harmfulness in purchase choices.

We also find that environmental concern needs to be analysed in conjunction with price sensitivity. A common method to assess the impact of price on green purchasing asks about consumers' willingness to pay for such goods (e.g., Moon and Balasubramanian, 2003; Royne et al., 2011), which relies on the assumption that green products always are more expensive than regular alternatives. By studying the conditional effect of perceived harmfulness on choices, we can circumvent this problematic assumption. Our findings clearly show that very price-sensitive consumers who perceive a product as harmful do not take this latter criterion into account, even if they are worried about environmental degradation. In contrast, consumers who do not embrace a logic of price minimisation focus strongly on environmental cues, even if they are not especially environmentally concerned. This finding suggests that price sensitivity may keep environmental attributes from being determinants of consumer choice.

However, these phenomena arise only in the dish soap category. For yoghurt, very different conclusions emerge. Even when consumers properly ascribe a high level of environmental harmfulness to the product, their choices do not seem affected. Vanclay et al. 
(2010) find a similar phenomenon for a similar product category, fresh milk: They observe no consumer response to the introduction of a carbon footprint label. This lack of consistency in the effectiveness of environmental labels across product categories represents a challenge for researchers, marketers and public policy makers: Why do consumers who perceive certain yoghurts as harmful to the environment fail to take this information into account in their purchase decisions? We posit that the explanation has to do with consumers' familiarity with environmental information in the category. Although our pre-test data offer some support for this familiarity-based explanation, we cannot ascribe the observed difference in the influence of perceived harmfulness to familiarity with environmental information with complete confidence. Therefore, we conducted Study 2 to affirm our proposed explanation.

\section{Study 2}

For this study, we used an alternative strategy to test the effect of familiarity with environmental information, focusing on individual differences in perceived familiarity. Because we therefore needed a product category for which familiarity with environmental information is highly dispersed, we considered the pre-test data and used paper towels.

\section{Method}

Respondents were also recruited on an empirical basis thanks to a snowball sampling method. In this online, quasi-experimental study, we first replicated our Study 1 pre-test. To hide the research objective from the respondents, we asked them to complete a 30-item questionnaire with various qualification scales. Then they viewed a picture of a pack of four rolls of paper towel (Figure 5). Using a projective scenario, respondents imagined themselves doing their weekly shopping in a supermarket and needing to buy paper towels. To avoid a possible brand bias, we used a brand sold in Belgium, unknown to the French sample of respondents. We also added the traffic light label from Study 1 to the packaging. All respondents were randomly assigned to a questionnaire that displayed either the red or the green light label, after which they rated their intentions to purchase the product on a 10-point scale. Most of these participants had been recruited from among the social networks of students in a master's level class; the initial pool included 145 people, and 126 questionnaires were usable (59 percent women, 9.5 percent between 18 and 25 years of age, 33.3 percent between 26 and 35 years; 27 percent between 36 and 45 years, 10.3 percent between 46 and 55 years, and 19.7 percent older than 56 years). In the random assignment, 56 percent of the respondents were exposed to the green traffic light. Chi-square tests revealed no significant association of the 
colour of the label viewed and either gender or age. We also checked that all participants were consumers of paper towels.

[Figure 5]

Results

The levels of familiarity with environmental information about different product categories matched those we found in the original pre-test. For paper towels, the mean familiarity with environmental information was $2.98(\mathrm{SD}=1.85)$. We divided the sample at the mean to create a binary familiarity variable ${ }^{1}$. The colour of the traffic light label strongly predicted perceived harmfulness $\left(\mathrm{F}=198.6, p<.001, \mathrm{M}_{\mathrm{red}}=6.21, \mathrm{M}_{\text {green }}=2.75\right.$; eta $\left.^{2}=.61\right)$.

To test our hypotheses, we conducted an ANOVA with purchase intention as the dependent variable. For paper towels, purchase intentions were higher for a green light label $(\mathrm{M}=5.58)$ than for a red light label $\left(\mathrm{M}=3.24 ; \mathrm{F}=31.22, p<.001 ;\right.$ eta $\left.^{2}=.206\right)$. When we included familiarity in the model as a random binary factor, it interacted significantly with the colour of the traffic light $(\mathrm{F}($ familiarity $\times$ colour $)=4.03, p=.043$; see Figure 6$)$. When perceived familiarity with environmental information about paper towels was low, purchase intentions still decreased for the red traffic light, but the negative effect was attenuated $\left(\mathrm{M}_{\text {low }}\right.$ familiarity $=3.76, \mathrm{M}_{\text {high familiarity }}=2.45$ ), in further support of $\mathrm{P} 2$.

[Figure 6]

\section{Discussion}

With Study 2, we confirm that the effect of eco-labels on consumers' purchase intentions depend on the degree to which consumers feel familiar with environmental information in the particular product category. When the eco-label indicates that the product (paper towels) has harmed the environment (red light), the disincentive associated with that label is stronger among consumers more familiar with environmental information. In other words, the negative effect of an eco-label for a harmful product is mitigated by a lack of familiarity. For eco-friendly products with positive labels, consumer familiarity with environmental information has no significant impact.

With these findings, we identify an interaction effect between consumer familiarity with environmental information and the information provided by the eco-label. The effect of familiarity could be explained by its ability to reduce consumer uncertainty; Harbaugh et al.

\footnotetext{
${ }^{1}$ Because of the limitations of such a discretization (Tybout, 2001), we replicated these analyses with a median split $(=3.25)$. The results were similar, though the F-statistic for the familiarity $\times$ colour interaction was significant only at $p=.054$.
} 
(2011) reveal that even small amounts of uncertainty can create confusion, which reduces or eliminates the efficacy of labels. Familiarity with environmental information instead would reduce consumer uncertainty and perhaps enhance the effectiveness of eco-labels.

If the goal of instituting eco-labelling programs in grocery stores is to guide consumers to select environmentally friendly products while avoiding harmful ones, managers first must encourage greater consumer familiarity with environmental information. Mandatory programs offer a radical approach (Banerjee and Solomon, 2003; Horne, 2009; Authors). Prior literature also highlights the importance of a simple information system that can be easily understood and maximise the chances that consumers use it at the point of purchase (Banerjee and Solomon, 2003). Information visibility is a related issue: If the information always appears in an unreadable format (e.g., small, inconvenient location), it will not be noticed by buyers. Finally, launching a mandatory, generalized eco-labelling program raises another problem: If the information is always present, consumers may simply become accustomed to it and stop paying attention to the information. To ensure environmental information remains vivid, several devices might highlight rating changes; for example, if a product switches from a red to an orange label, the packaging should feature a specific scheme (e.g., larger sticker on the product) to grab consumers' attention. Specific displays such as this could be implemented for limited periods of time and apply to all rating changes, whether negative or positive.

\section{General discussion and conclusion}

\section{Theoretical contributions}

This research offers new insights into the conditions for effective environmental labelling of grocery products. By providing information about the environmental harmfulness of products, labelling influences purchase behaviours (choice and intention). In general, ecolabels promote the purchase of green products and discourage the purchase of less environmentally friendly products. However, among the major theoretical contributions of our research, we have shown that this influence is moderated by three consumer factors: price sensitivity, environmental concern and familiarity with environmental information. Consumer familiarity with environmental information varies across product categories, so the effectiveness of labels similarly depends on the product category. Furthermore, environmental concern turns out to have a much smaller influence on consumers' decisions than price sensitivity. Adapting the concept of familiarity to the context of environmental information is 
also an interesting contribution of this work. This concept turns out be crucial in order to understand the differences in consumer behaviour across product categories.

Finally, another theoretical contribution of our model lies in the moderator role given to environmental concern. As mentioned previously, environmental concern is one of the most studied variables in the literature on the determinants of green behaviour. In most of the studies, it is apprehended as a direct antecedent of behaviour or behaviour intent. Many authors, however, deplored the poor predictive power of the concept which led to consider it as an indirect determinant (e.g. Bamberg, 2003). In this study, we suggest that environmental concern could rather be apprehended as moderator variable together with other individual predispositions.

\section{Managerial implications}

Unlike most previous investigations of eco-labels, this study tackles a specific situation in which all products, independent of their category, take labels that can be favourable or unfavourable. Although such a generalized scheme does not currently exist, public policy measures seem to be evolving in favour of mandatory programs; the French government is closely examining the possibility. Such political measures could have a considerable impact on in-store customer behaviour and probably also retailing practices. To remain competitive, store brands would need to make substantial progress with regard to their ecological features. Compared with national brands, they continue to lag in terms of sustainability and environmental information (Carrero and Valor, 2012). However, in the short term store brands with a clear price positioning do not face direct threats, because their core target likely consists of highly price-sensitive consumers (Glynn and Chen, 2009). Over time though, we might expect some shock as consumers gain familiarity with environmental information, which ultimately may make this choice criterion more salient.

The differences observed across product categories also may have serious implications for retailers if generalized labelling becomes mandatory. Depending on their positioning, some grocery stores may need to revise their product assortment and shelf management. For the product categories in which environmental information is an important selection criterion, advertising at the point of sale could offer a new promotional tool, highlighting which brands have the lowest environmental impact.

The crucial role of familiarity in our research also suggests, ironically, that greenwashing might have at least one positive impact: By promoting the so-called ecological attributes of their products, companies involved in such practices contribute to exposing 
consumers to environmental information. Even if the information is inaccurate or exaggerated, this process still increases familiarity with environmental information. However, in this case greater familiarity coincides with greater scepticism about ecological allegations.

\section{Societal and economic implications}

Overall, our findings suggest that a mandatory eco-labelling policy could be effective in encouraging consumers to purchase environmentally friendlier products. However, the adoption of such a policy would imply additional costs related to the application of the labelling scheme and its monitoring (Caputo et al., 2013). Despite these costs, the implementation of mandatory labelling programs by governments would still be profitable given the great impact it could have on the societal level. Contrarily, if eco-labels remain based on a voluntary approach, many producers or retailers would be reluctant to provide that information and consumers would still be lacking the necessary material to judge the different products objectively.

There is now a scientific consensus in favour of a significant change in human activities patterns in order to preserve conditions for human life on Earth (e.g. Steffen et al., 2005). However, this change can only be attained if individuals become more aware of their responsibility as consumers. Thus, they should be informed more thoroughly about the environmental risks related to their consumption. This should be done at a general level and for every product category, by public authorities, companies, non-public organizations, etc. These efforts could not only strengthen their environmental concern but also enhance its effects compared to price sensitivity. As mentioned earlier, indeed, our results indicate that products' perceived harmfulness does not affect choice when consumers are highly price-sensitive. This is a major problem in a time of economic crisis with multiple pressures on purchasing power. The actual or perceived price premium associated with green products is a hurdle that has to be overcome. In addition, eco-labelling programs should be harmonized by the regulator in order to gain visibility and generate greater familiarity and greater confidence from the consumers' point of view.

\section{Limitations and future perspectives}

In our attempt to understand discrepancies across product categories, we only focused on familiarity, but other differences might have impacts as well. The two products we examined in Study 1 also differ in their buying motives. For example, health motives likely are far more prevalent among yoghurt consumers than among shoppers buying dish soap. More selfish 
motivations also could explain why consumers take environmental information into greater or lesser account; this issue should be the subject of further investigations. Additional individual variables should also have been controlled for. In study 1, for instance, the choice situation used in the experiment included both a premium brand and a store brand. As a result, it is likely that respondents' choice was affected by their attitude towards private labels, which we did not measure. Moreover, even though we took into account the impact of environmental concern, it would have been relevant to also assess the effect of scepticism towards eco-labels. With the increasing number of pro-environmental claims and sustainable labels, consumers are indeed expressing growing scepticism (Mohr et al, 1998) which is likely to affect their purchasing behaviour. Future research should assess the impact of consumers' trust in environmental labels in the case of a mandatory labelling programme. However since labels implemented by governments where shown to be more trusted than labels by companies (Atkinson and Rosenthal, 2014), mandatory labelling is likely to create less resistance.

Finally, we note other limitations of our studies due to our use of a fictive eco-label (traffic light). We had to draw respondents' attention on the labelling scheme to explain its functioning, which likely made that information more salient than it might be in a real-world shopping situation. Additional research should replicate our studies in more realistic situations, perhaps using experimental supermarkets. Moreover, consumers' reactions are likely to change during the implementation period of eco-labelling programs. Therefore it seems necessary to conduct longitudinal studies to understand how the mechanism of eco-labels' efficacy evolves.

\section{REFERENCES}

60 millions de consommateurs (2013), « L'attrait lucide pour le naturel, 60 millions de consommateurs », 168, 12-16.

Alba, J.W. and Hutchinson, J. W. (1987), "Dimensions of consumer expertise", Journal of Consumer Research, Vol. 13, No. 4, pp. 411-454.

Atkinson, L. and Rosenthal, S. (2014), "Signaling the Green Sell: The Influence of Eco-Label Source, Argument Specificity, and Product Involvement on Consumer Trust", Journal Of Advertising, Vol. 43, No. 1, pp. 33-45.

Balasubramanian, S.K. and Cole, C. (2002), "Consumers' Search and Use of Nutrition Information: The Challenge and Promise of the Nutrition Labeling and Education Act", Journal of Marketing, Vol. 66, No. 3, pp. 112-127. 
Bamberg, S. (2003), "How does environmental concern influence specific environmentally related behaviors? A new answer to an old question", Journal of Environmental Psychology, Vol. 23, No. 1, pp. 21-32.

Bandura, A. (1977), Social Learning Theory, New York: General Learning Press.

Banerjee, A. and Solomon, B.D. (2003), "Eco-labeling for energy efficiency and sustainability: a meta-evaluation of US programs", Energy Policy, Vol. 31, pp. 109-123.

Bettman, J.R. and Park, C. W. (1980), "Effects of prior knowledge and experience and phase of the choice process on consumer decision processes: A protocol analysis", Journal of Consumer Research, Vol. 7, No. 3, pp. 234-248.

Bradu, C., Orquin, J.L. and Thøgersen, J. (2013), "The Mediated Influence of a Traceability Label on Consumer's Willingness to Buy the Labelled Product", Journal of Business Ethics

Brécard D., Hlaimi, B., Lucas, S., Perraudeau, Y. and Salladarré, F. (2009), "Determinants of demand for green products: An application to eco-label demand for fish in Europe", Ecological Economics, Vol. 69, № 1, pp. 115-125.

Brucks, M. (1985), "The Effects of Product Class Knowledge on Information Search Behavior”, Journal of Consumer Research, Vol. 12, No. 1, pp. 1-16.

Caputo, V., Vassilopoulos A., Nayga JR., R. M. and Canavari, M. (2013), "Welfare Effects of Food Miles Labels", Journal of Consumer Affairs, Vol. 47, No. 2, pp. 311-327.

Carrero, I and Valor, C. (2012), “CSR-labelled products in retailers' assortment: A comparative study of British and Spanish retailers", International Journal Of Retail \& Distribution Management, Vol. 40, No. 8, pp. 629-652.

Casadesus-Masanell, R., Crooke, M., Reinhardt, F., and Vasishth, V. (2009), 'Households' willingness to pay for "green" goods: Evidence from Patagonia's introduction of organic cotton sportswear", Journal of Economics \& Management Strategy, Vol. 18, No. 1, pp. 203 233.

Chattopadhyay, A., and Basu, K. (1990). "Humor in advertising: The moderating role of prior brand evaluation". Journal of Marketing Research, Vol. 27, № 4, pp. 466-476.

Delmas, M.A., and Grant, L.E. (2014), "Eco-Labeling Strategies and Price-Premium: The Wine Industry Puzzle", Business \& Society, Vol. 53, º 1, pp. 6-44.

D'Souza, C., Taghian, M. and Lamb, P. (2006), “An empirical study on the influence of environmental labels on consumers", Corporate Communications: An International Journal, Vol. 11, N², pp. 162-173.

Erdem T., Swait, J. and Louvière, J. (2002), “The impact of brand credibility on consumer price sensitivity", International Journal of Research in Marketing, Vol. 19, No. 1 pp. 1-19. 
European Commission (2008), Attitudes of European citizens towards the environment, Special Eurobarometer, 295.

Fishbein, M. (1963), “An investigation of relationships between beliefs about an object and the attitude toward that object”, Human Relations, Vol. 16, pp. 233-240.

Gam, H. C., Farr, C.; and Mihyun, K. (2010), "Quest for the eco-apparel market: a study of mothers' willingness to purchase organic cotton clothing for their children", International Journal of Consumer Studies, Vol. 34, No 6, pp. 648-656.

Glynn, M.S. and Chen, S. (2009), "Consumer-factors moderating private label brand success: further empirical results ”, International Journal of Retail \& Distribution Management, Vol. 37, No. 11, pp.896-914.

Goldsmith, R.E. and Newell, S.J. (1997), "Innovativeness and price sensitivity: managerial, theoretical and methodological issues", Journal of Product \& Brand Management, Vol. 6 №3, pp.163 - 174

Grankvist, G., Dahlstrand, U. and Biel, A. (2004), “The Impact of Environmental Labelling on Consumer Preference: Negative vs. Positive Labels", Journal of Consumer Policy, 27, 213 230.

Harbaugh, R., Maxwell, J.W. and Roussillon, B. (2011), "Label Confusion: the Groucho effect of uncertain standards", Management Science, Vol. 57, No. 9, pp. 1512-1527.

Hayes, A. F. (2012), "PROCESS: A versatile computational tool for observed variable mediation, moderation, and conditional process modelling", [White paper]. Retrieved from http://www.afhayes.com/public/process2012.pdf

Hayes, A. F. and Matthes, J. (2009), "Computational procedures for 'probing interactions in linear and logistic regression: SPSS and SAS implementations", Behavior Research Methods, Vol. 41, pp. No. 3, pp. 924-936.

Hoek, J., Roling, N. and Holdsworth, D. (2013), "Ethical claims and labelling: An analysis of consumers' beliefs and choice behaviours", Journal of Marketing Management, Vol. 29, $\mathrm{N}^{\circ}$ 7/8, pp. $772-792$.

Honnold, J. A. (1984), "Age and environmental concern : some specification of effects", The Journal of Environmental Education, Vol. 16, No 1, pp. 4-9.

Horne, R.E. (2009), "Limits to labels: The role of eco-labels in the assessment of product sustainability and routes to sustainable consumption", International Journal of Consumer Studies, Vol. 33, No 2, pp. 175-182.

Hunt, S. D. and Vitell, S. J. (2006), "The general theory of marketing ethics: a revison and three questions", Journal of Macromarketing, Vol. 26, No. 2, pp. 1-11. 
Johnston, R.J., Roheim, C.A., Donath, H. and Asche F. (2001), "Measuring Consumer Preferences for Ecolabeled Seafood: An International Comparison", Journal of Agricultural and Resource Economics, Vol. 26, No. 1, pp. 20-39.

Johnson, E.J. and Russo, J.E. (1984), "Product familiarity and learning new information", Journal of Consumer Research, Vol. 11, No.1, pp. 542-550.

Jones, T. M. (1991), "Ethical decision making by individuals in organizations: an issuecontingent model", Academy of Management Review, Vol. 16, №2, pp. 366-395.

Kilbourne, W. and Pickett, G. (2008), "How materialism affects environmental beliefs, concern, and environmentally responsible behavior”, Journal of Business Research, Vol. 61, Nº, pp. 885-893.

Lichtenstein, D., Ridgway, N.,and Netemeyer, R. (1993). "Price perceptions and consumer shopping behavior: a field study". Journal of Marketing, Vol. 30, No. 2, pp. 234-246.

Mainieri, T., Barnett, E., Vaidero, T., Unipan, J.,and Oskamp, S. (1997), “Green buying: The influence of environmental concern on consumer behaviour", The Journal of Social Psychology, Vol. 137, No. 2, pp. 189-204.

Marks, L.J. and Olson, J.C (1981), Toward a cognitive Structure conceptualization of product familiarity, in Kent B. Monroe, Ann Abor (eds.), NA - Advances in Consumer Research, Vol. 8, MI : Association for Consumer Research, pp. 145-150.

Moon, W. and Balasubramanian, S.K. (2003), "Willingness to pay for non-biotech foods in the U.S. and U.K.", Journal of Consumer Affairs, Vol. 37, No. 2, pp. 317-339.

Mohr, L. A., Eroglu, D., \& Ellen, P. (1998), "The development and testing of a measure of skepticism toward environmental claims in marketers' communications", Journal of Consumer Affairs, Vol. 32, No. 1, pp 30-55

Moorman, C. (1990), "The effects of stimulus and consumer characteristics on the utilization of nutrition information", Journal of Consumer Research, Vol. 17, No. 3, pp. 362-374.

Park, J. and Ha, S. (2012), "Understanding pro-environmental behavior: A comparison of sustainable consumers and apathetic consumers", International Journal of Retail \& Distribution Management, Vol. 40 No. 5, pp. 388-403.

Park, J. and Stoel, L. (2005), "Effect of brand familiarity, experience and information on online apparel purchase", International Journal of Retail \& Distribution Management, Vol. 33 No. 2, pp.148-160.

Pickett-Baker, J. and Ozaki, R. (2008), "Pro-environmental products: marketing influence on consumer purchase decision", Journal of Consumer Marketing, Vol. 25, No. 5, pp. 281-293. 
Royne, M.B., Levy, M. and Martinez, J. (2011), “The public health implications of consumers' environmental concern and their willingness to pay for an eco-friendly product", Journal of Consumer Affairs, Vol. 45, No. 2, pp. 329-343.

Sammer, K. and Wüstenhagen, R. (2006), "The influence of eco-labelling on consumer behaviour - results of a discrete choice analysis for washing machines", Business Strategy and the Environment, Vol. 15, No. 3, pp. 185-199.

Schlegelmilch B., Bohlen, G. and Diamantopoulos, A. (1996), "The link between green purchasing decisions and measures of environmental consciousness", European Journal of Marketing, Vol. 30, No. 5, pp. 35-55

Schwepker, C. and Cornwell, T. (1991). "An Examination of Ecologically Concerned Consumers and Their Intention to Purchase Ecologically Packaged Products", Journal of Public Policy and Marketing, Vol. 10, pp. 77-101.

Slonim, R. and Garbarino, E. (1999). "The Effect of Price History on Demand as Mediated by Perceived Price Expensiveness". Journal of Business Research, Vol. 45, N¹, pp. 1-14.

Steffen W., Sanderson A., Tyson P.D., Jäger J., Matson P.A., Moore III B., Oldfield F. Richardson K., Schellnhuber H.-J., Turner B.L. and Wasson R.J. (2005), Global change \& the Earth system: A planet under pressure, Springer.

Stern, P.C. (2000), "Toward a Coherent Theory of Environmentally Significant Behavior", Journal of Social Issues, 56, 3, 407-424.

Stern, P. C., Diet, T., Kalof, L., and Guagnano, G. A. (1995), "Values, Beliefs, and Proenvironmental Action: Attitude Formation Toward Emergent Attitude Objects", Journal Of Applied Social Psychology, Vol. 25, No. 18, pp. 1611-1636.

Tanner, C. and Kast, S. (2003), "Promoting sustainable consumption: Determinants of green purchases by swiss consumers", Psychology \& Marketing, Vol. 20, No. 10, pp. 883-902.

Thøgersen, J. (2000), "Psychological determinants of paying attention to eco-labels in purchase decisions: Model development and multinational validation", Journal of Consumer Policy, Vol. 23, $\mathrm{N}^{\circ} 3$, pp. 285-313.

Thøgersen, J., Haugaard, P., and Olesen, A. (2010), "Understanding consumer responses to ecolabels", European Journal of Marketing, Vol. 44, No. 11/12, pp. 1787 - 1810.

Thøgersen, J., Jørgensen, A.-K. and Sandager, S. (2012), "Consumer decision making regarding a "green" everyday product" Psychology and Marketing, Vol. 29, $\mathrm{N}^{\circ}$ 4, pp. 187 197.

Tybout, A. (2001), "Treating an individual difference predictor as continuous or categorical”, Journal of Consumer Psychology, Vol. 10, No. 1/2, pp. 48-49. 
Uchida, H., Roheim, C. A., Wakamatsu, H. and Anderson, C. M. (2014), "Do Japanese consumers care about sustainable fisheries? Evidence from an auction of ecolabelled seafood", Australian Journal of Agricultural and Resource Economics, Vol. 58, N² pp. 263-280.

Vanclay, J.K., J. Shortiss, S., Aulsebrook, A.M. Gillespie, B.C. Howell, Johanni, R., Maher M.J., Mitchell, K.M., Stewart, M.D. and Yates, J. (2011), "Customer response to carbon labelling of groceries", Journal of Consumer Policy, Vol. 34, No. 1, pp. 153-160.

Wessells, C.R., Johnston, R.J. and Donath, H. (1999) "Assessing consumer preferences for ecolabeled seafood: the influence of species, certifier, and household attributes", American Journal of Agricultural Economics, Vol. 81, N 5, pp. 1084-1089.

Zelezny, L. C., Chua, P.-P., and Aldrich, C. (2000), "New ways of thinking about environmentalism: elaborating on gender differences in environmentalism", Journal of Social Issues, Vol. 56, No. 3, pp. 443-457. 


\section{TABLES}

\begin{tabular}{lcccccc}
\hline & Mean & SD & \multicolumn{5}{c}{ Paired-sample t test } \\
& & & (1) & (2) & (3) & (4) \\
\hline Yoghurts (1) & 1.6406 & .90 & - & - & - & - \\
Meat tray (2) & 1.9336 & 1.20 & $-3.05 * *$ & - & - & - \\
Dishwashing liquid (3) & 3.8164 & 1.60 & $-12.50^{* * *}$ & $-10.51 * * *$ & - & - \\
Dry pasta (4) & 1.8086 & 1.07 & $-2.56^{*}$ & 1.32 n.s. & $11.13 * * *$ & - \\
Paper towel (5) & 3.0977 & 1.81 & $-9.97 * * *$ & $-7.32 * * *$ & $5.08 * * *$ & $-8.53 * * *$ \\
\hline
\end{tabular}

Table 1 - Descriptive statistics and paired sample t-test for familiarity with environmental information

\begin{tabular}{|c|c|c|c|c|c|}
\hline & $\begin{array}{c}\mathrm{NB}^{\mathrm{a}} \text { green label } \\
\mathrm{SB}^{\mathrm{b}} \text { red label }\end{array}$ & $\begin{array}{l}\text { NB red label } \\
\text { SB green label }\end{array}$ & $\begin{array}{l}\text { NB red label } \\
\text { SB red label }\end{array}$ & $\begin{array}{l}\text { NB green label } \\
\text { SB green label }\end{array}$ & Total \\
\hline Dishwashing liquid & 46 & 42 & 41 & 43 & 172 \\
\hline Yoghurts & 46 & 43 & 33 & 39 & 161 \\
\hline Total & 92 & 85 & 74 & 82 & 333 \\
\hline
\end{tabular}

a: National Brand; b: Store Brand

Table 2 - The full factorial design 


\begin{tabular}{|c|c|c|c|c|}
\hline \multirow[b]{3}{*}{ Independent variables } & \multicolumn{4}{|c|}{$\begin{array}{l}\text { DV : Choice of Store Brand } \\
\text { over National Brand }\end{array}$} \\
\hline & \multicolumn{2}{|c|}{ Model 1} & \multicolumn{2}{|c|}{ Model 2} \\
\hline & B & $\operatorname{Exp}(B)$ & $\mathbf{B}$ & $\operatorname{Exp}(B)$ \\
\hline Constant & $1.153 * * *$ & 3.167 & $1.84 * * *$ & 6.32 \\
\hline Perceived quality (NB-SB) & $-.74 * * *$ & .48 & $-.86 * * *$ & .42 \\
\hline Perceived price (NB-SB) & $.32 * * *$ & 1.38 & $.38^{* * *}$ & 1.46 \\
\hline Attitude towards the brand (NB-SB) & $-.29 * * *$ & .75 & $-.24 * *$ & .78 \\
\hline Perceived harmfulness (NB-SB) & $.21 * * *$ & 1.23 & $.42 * * *$ & 1.43 \\
\hline $\begin{array}{l}\text { Product category }(0=\text { Dish soap; } \\
1=\text { Yoghurts })\end{array}$ & - & - & $-1.40 * * *$ & 4.04 \\
\hline Harmfulness (NB-SB)* Product Category & - & - & $-.39 * *$ & 1.47 \\
\hline Hosmer Lemeshow $\mathrm{Chi}^{2}$ & \multicolumn{2}{|c|}{ 9.26(8) n.s. } & \multicolumn{2}{|c|}{$8.50(8)$ n.s. } \\
\hline Nagelkerke $\mathrm{R}^{2}$ & \multicolumn{2}{|c|}{.39} & \multicolumn{2}{|c|}{.46} \\
\hline Sample & \multicolumn{4}{|c|}{ Dish soap + Yoghurts } \\
\hline
\end{tabular}

Table 3 - Effect of product category on the link between perceived harmfulness and choice 


\begin{tabular}{|c|c|c|c|c|c|c|}
\hline \multirow[b]{3}{*}{ Independent variables } & \multicolumn{6}{|c|}{ Dependent Variable : Choice of Store Brand over National Brand } \\
\hline & \multicolumn{2}{|c|}{ Model 3} & \multicolumn{2}{|c|}{ Model4 } & \multicolumn{2}{|c|}{ Model 5} \\
\hline & $\mathbf{B}$ & $\operatorname{Exp}(\mathbf{B})$ & B & $\operatorname{Exp}(\mathbf{B})$ & B & $\operatorname{Exp}(\mathbf{B})$ \\
\hline Constant & $1.08^{* * *}$ & 5.09 & $1.78^{* * *}$ & 5,94 & $1.76^{* * *}$ & 5.79 \\
\hline Perceived quality (NB-SB) & $-.72 * * *$ & .49 & $-.70^{* * *}$ & , 49 & $-.67 * * *$ & .51 \\
\hline Perceived price (NB-SB) & $.32 * * *$ & 4.49 & $.45^{* * *}$ & 1,57 & $.49 * * *$ & 163 \\
\hline $\begin{array}{l}\text { Attitude towards brand } \\
\qquad \text { (NB-SB) }\end{array}$ & $-.57 * *$ & .64 & $-.38 * *$ & ,68 & $-.42 * *$ & .65 \\
\hline $\begin{array}{l}\text { Perceived harmfulness (NB- } \\
\qquad \text { SB) }\end{array}$ & $.38^{* *}$ & 1.46 & $.20 * *$ & 1,22 & $.31 * *$ & 1.36 \\
\hline Environmental concern & .31.n.s & .68 & - & - & .11 n.s. & 1.11 \\
\hline Harmfulness * Env.concern & $.21 *$ & 1.21 & - & - & $.20^{*}$ & 1.22 \\
\hline Price sensitivity & - & - & $.75 * * *$ & 2,12 & $.71 * * *$ & 2.02 \\
\hline Harmfulness * Price sens. & - & - & $-.43^{*}$ & 0,64 & $-.28 *$ & .75 \\
\hline Hosmer Lemeshow $\mathrm{Chi}^{2}$ & \multicolumn{2}{|c|}{$9.21(8)$ n.s. } & \multicolumn{2}{|c|}{$6.92(8)$ n.s. } & \multicolumn{2}{|c|}{$7.23(8)$ n.s. } \\
\hline Nagelkerke $\mathrm{R}^{2}$ & \multicolumn{2}{|c|}{.57} & \multicolumn{2}{|c|}{.57} & \multicolumn{2}{|c|}{.59} \\
\hline Sample & \multicolumn{6}{|c|}{ Dish soap } \\
\hline
\end{tabular}

Table 4 - Effect of environmental concern and price sensitivity on perceived harmfulness/choice consistency 


\section{FIGURES}

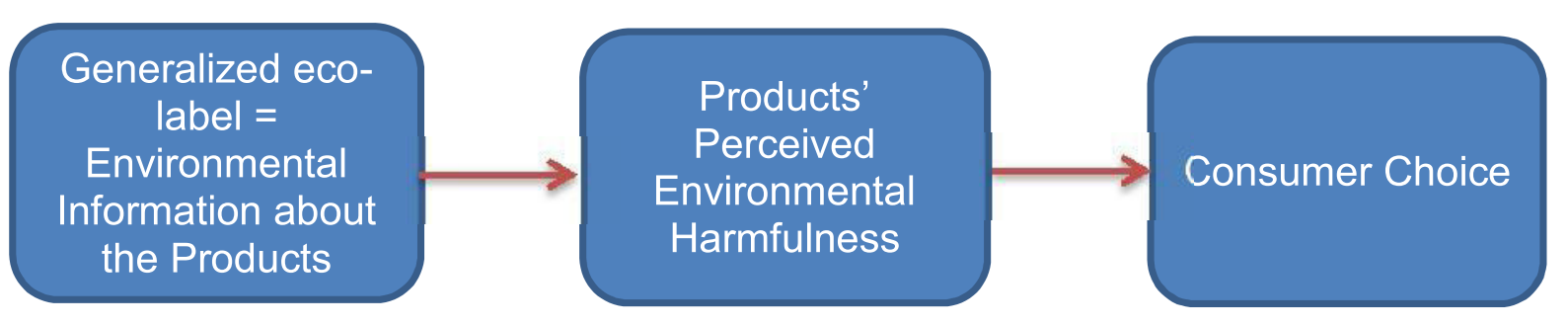

Figure 1 - Main mechanism of eco-labeling on consumer choice

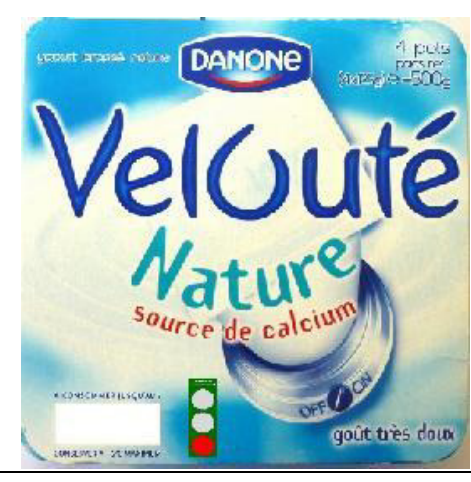

\section{Danone Stirred \\ natural yogurts}

Pack of $4 \times 125 g$

yogurts

$1.29 €$

$(2.58 € / \mathrm{kg})$

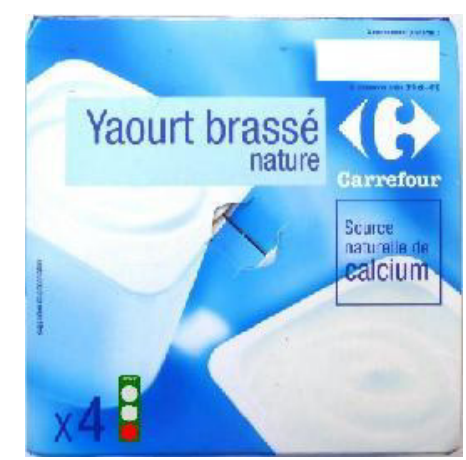

Carrefour Stirred

natural yogurts

Pack of $4 \times 125 \mathrm{~g}$

yogurts

$0.95 €$

$(1.90 € / \mathrm{kg})$

Figure 2- Example of choice configuration
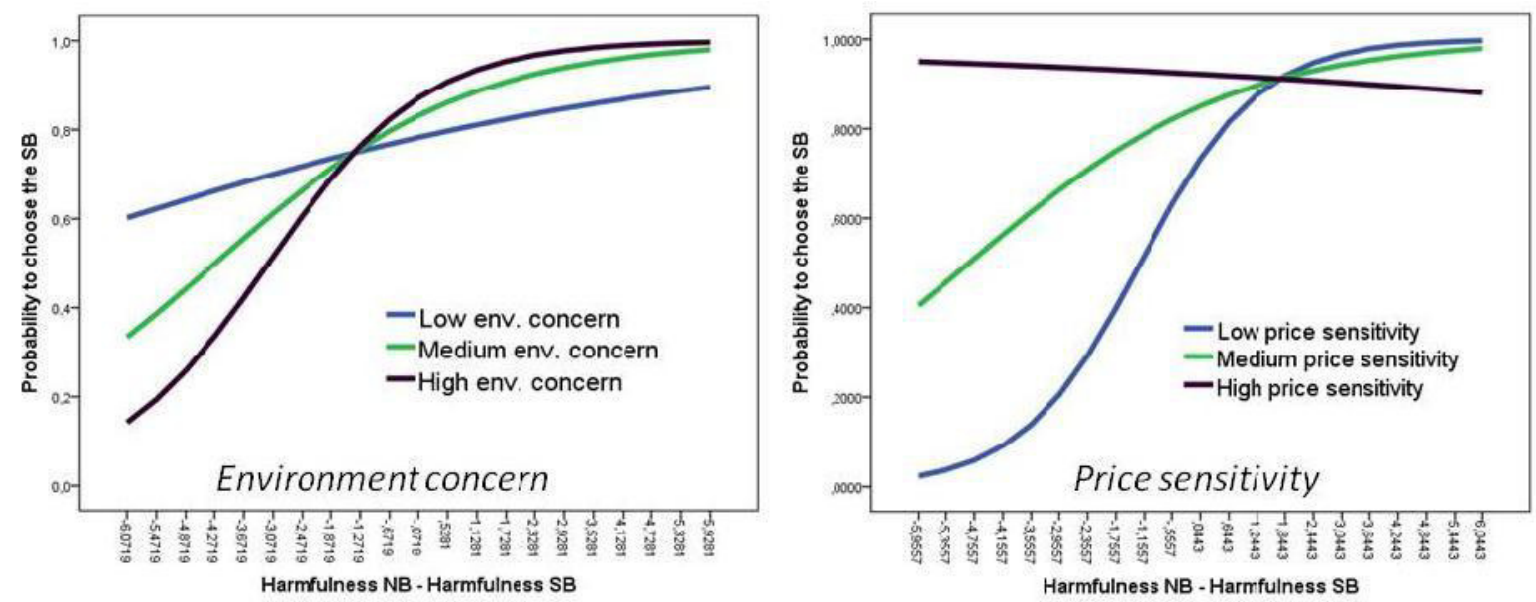

Figure 3 -Moderator effects of environmental concern and price sensitivity 


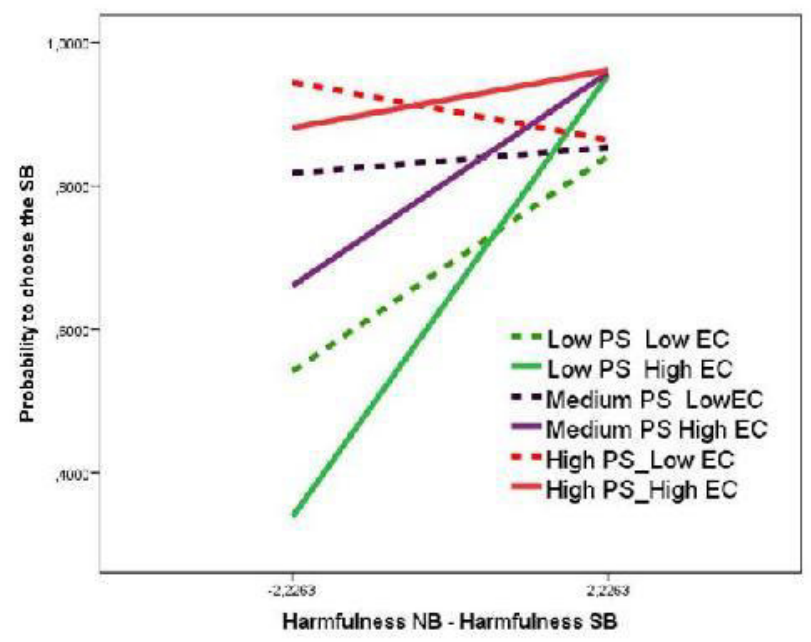

Figure 4 - Combined effects of environment concern and price sensitivity

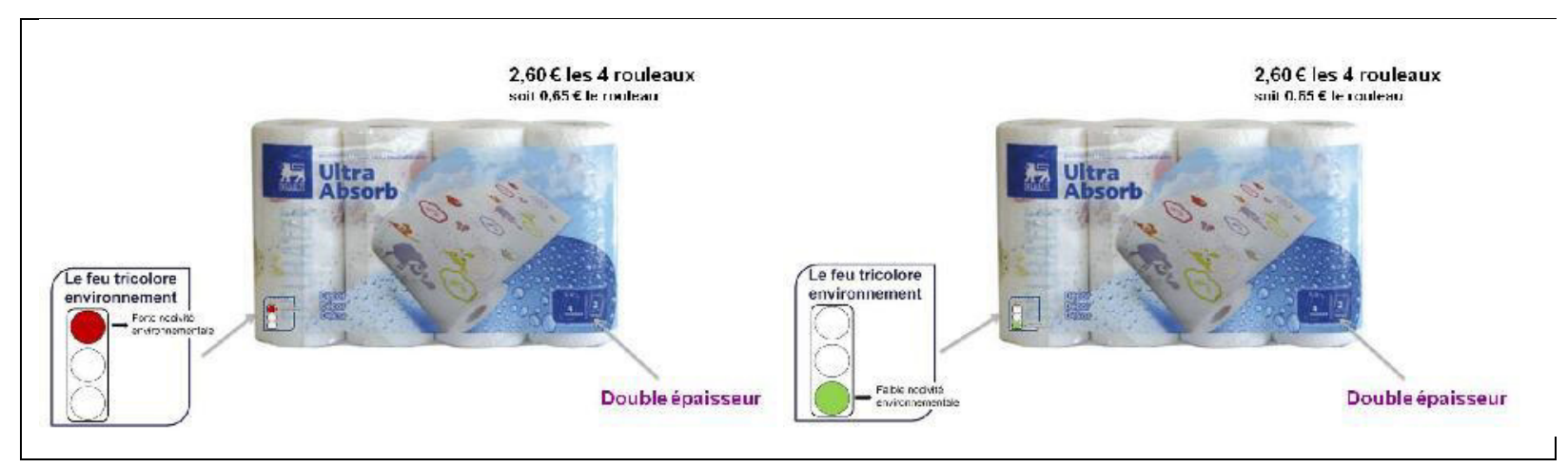

Figure 5 -Product visuals used in study 2

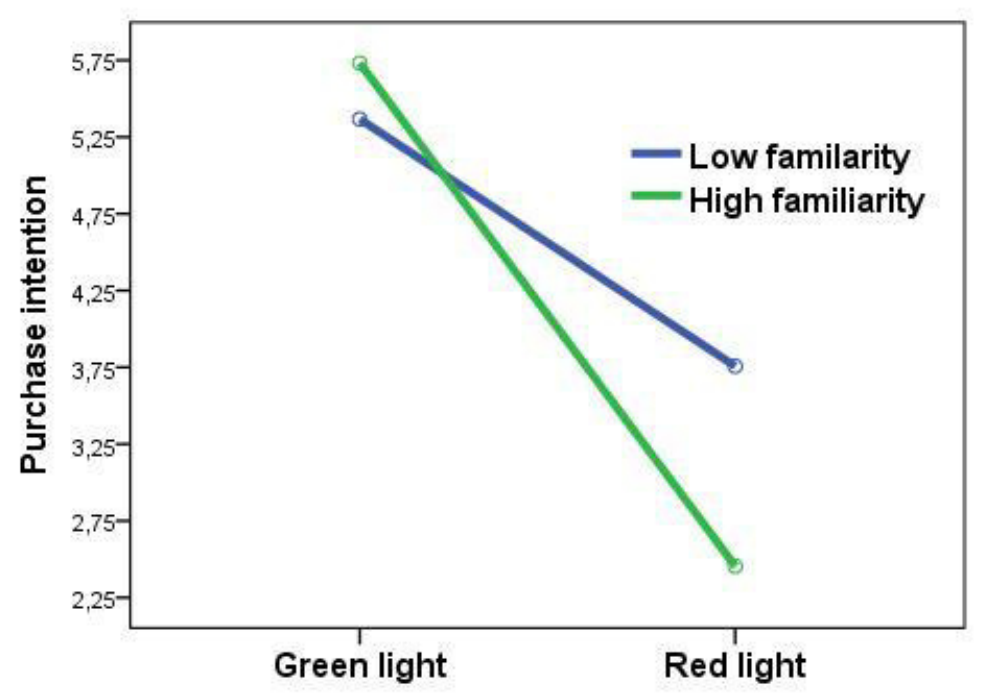

Figure 6 - Illustration of the moderator effect of familiarity with environmental information 